\title{
O conhecimento de enfermeiros de dois hospitais do Extremo Sul Catarinense a respeito da Tetralogia de Fallot
}

\author{
Mônica Waterkemper Casagrande*, Gabriela Acordi da Silva, M.Sc. **
}

${ }^{*}$ Graduada em enfermagem pela UNESC (Universidade do Extremo Sul Catarinense), Criciúma/SC,

**Enfermeira, docente do curso de Enfermagem da Universidade do Extremo Sul Catarinense

Extraído do Trabalho de Conclusão de Curso de Graduação em Enfermagem da Universidade do Extremo Sul Catarinense (UNESC) intitulado "O Conhecimento de enfermeiros de dois hospitais do extremo Sul Catarinense a respeito da Tetralogia de Fallot"

\begin{abstract}
Resumo
Este estudo objetivou verificar o conhecimento de enfermeiros de dois hospitais do extremo Sul Catarinense sobre a Tetralogia de Fallot. Trata-se de um estudo descritivo de abordagem qualitativa, realizado entre março e junho de 2011. Foram alvo deste estudo onze enfermeiros, que foram entrevistados e os dados foram organizados e analisados na forma de análise temática. Conforme os relatos dos entrevistados percebe-se que a maioria não possui muitos conhecimentos sobre a patologia, o que pode desencadear um atendimento inadequado à criança portadora de Tetralogia de Fallot e a seus familiares, não conseguindo instruí-los quando necessário. Sugere-se a realizaçáo de novos estudos sobre a patologia, aumentando o conhecimento dos profissionais de saúde e até mesmo de familiares de portadores de Tetralogia de Fallot que hoje buscam o maior número de informaçóes acerca da patologia.
\end{abstract}

Palavras-chave: conhecimento, tetralogia de Fallot, enfermagem pediátrica.

\section{Abstract \\ Knowledge of nurses of two hospitals in the southern of Santa Catarina about the Tetralogy of Fallot}

This study aimed at verifying nurses knowledge of two hospitals in the southern of Santa Catarina about the Tetralogy of Fallot. This is a descriptive qualitative study, carried out from March to June 2011. Eleven nurses were interviewed in this study and data were organized in the form of thematic analysis. According to the nurses, most of them do not have much knowledge about the pathology, which can initiate an inadequate care to children with Tetralogy of Fallot and to their families, failing to instruct them as needed. We suggest carrying out further studies about the pathology, improving knowledge of healthcare 
professionals and also relatives of patients with Tetralogy of Fallot who nowadays are looking for more information about the pathology.

Key-words: knowledge, tetralogy of Fallot, pediatric nursing.

\section{Resumen}

\section{El conocimiento de enfermeros de dos hospitales del Extremo Sur de Santa Catarina acerca de la Tetralogía de Fallot}

Este estudio tuvo como objetivo verificar el conocimiento de enfermeros de dos hospitales del Extremo Sur de Santa Catarina sobre Tetralogía de Fallot. Se trata de un estudio descriptivo de abordaje cualitativo, realizado entre marzo y junio de 2011. Fueron objeto de estudio once enfermeros, que fueron entrevistados y cuyos datos fueron organizados y analizados en forma de análisis temática. De acuerdo con los relatos de los entrevistados se percibe que la mayoría no posee mucho conocimiento sobre la enfermedad, que puede desencadenar una atención inadecuada a los niños con Tetralogía de Fallot y sus familiares, no dando las instrucciones adecuadas cuando sea necesario. Se sugiere la realización de nuevos estudios sobre la enfermedad, aumentando conocimientos de profesionales de la salud y también de los familiares de portadores de Tetralogía de Fallot que hoy buscan mayores informaciones acerca de la patología.

Palabras-clave: conocimiento, tetralogía de Fallot, enfermería pediátrica.

\section{Introdução}

Na vida de um casal, geralmente a gravidez traz muita alegria e expectativas a respeito da criança que irá nascer. Os pais fazem planos para o futuro de seu filho ou filha, imaginando como será uma criança saudável e feliz. Mas infelizmente não é sempre que acontece desta forma [1].

Ainda na vida uterina os pais podem receber a notícia de que seu bebê possui alguma má formação ou doença, às vezes tratável outras não. Esta notícia pode desencadear vários sentimentos em todos os envolvidos com a criança, principalmente os pais, que muitas vezes podem se culpar ou se sentirem frustrados [1].

Dentre os problemas encontrados estão as cardiopatias congênitas que podem ser definidas por uma alteração estrutural grave do coração ou grandes vasos da base e que contêm uma significância potencial alta [2].

Muitas anomalias congênitas não possuem causas exatas, o que gera maior desconforto para os pais. Kenner [3] afirma que “...algumas têm sido vinculadas a distúrbios genéticos ou cromossômicos, rubéola congênita, exposição a radiação, diabetes materno e uso de drogas pela mãe. A idade avançada da mãe também tem sido associada a certas anomalias..."

Elas compreendem desde defeitos que evoluem de forma assintomática até aqueles de alta taxa de mortalidade. A análise de prevalência apresenta diferentes resultados dependendo da idade da população analisada [4].

De acordo com a Organização Mundial de Saúde (OMS), no Brasil, as doenças cardiovasculares são responsáveis por 16,7 milhôes de mortes ao ano, com projeçóes para o ano de 2020 de persistirem como causa principal de mortalidade e incapacitação [5].

No estudo feito por Rivera et al. [4], no período compreendido entre agosto de 1999 e julho de 2002, dos 358 recém-nascidos avaliados foram encontrados 49 (14\%) com malformaçóes cardíacas congênitas, sendo destes 3 (6,2\%) casos de Tetralogia de Fallot. Dados de diferentes estudos mostram diferentes índices de incidência, variando de 4/1.000 a 50/1.000 cardiopatia congênitas/recém-nascido. Essa ampla variação demonstra a dificuldade de obter dados no que diz respeito à incidência e à prevalência. Outro estudo realizado no Brasil demonstrou uma prevalência de aproximadamente 5,5/1.000 cardiopatias/nascidos vivos [4].

Segundo o levantamento realizado por Miyague et al. [6], em um hospital infantil do Paraná, o índice de Tetralogia de Fallot dos atendidos entre os anos de 1995 e 1997 foi de 6,9\% (136 casos) dos pacientes estudados, representando a cardiopatia cianótica mais frequente, sendo que o hospital recebe pacientes dos estados do Paraná e Santa Catarina.

Dentre as cardiopatias congênitas existentes, a Tetralogia de Fallot (T4F) destaca-se pela sua raridade, tendo como características quatro más 
formaçóes cardíacas e tratamento complexo, sendo considerada de alto nível de mortalidade infantil.

$\mathrm{Na}$ Tetralogia de Fallot apresentam-se dextroposição da aorta, estenose pulmonar, hipertrofia ventricular direita e comunicação interventricular. As manifestaçóes clínicas mais presentes são a cianose e sopro cardíaco alto. Seu tratamento consiste principalmente de cirurgia corretiva, o que traz espanto e medo por parte dos familiares.

Segundo Lopez [2], a prevalência da T4F é de 0,21 por 1.000 nascidos vivos, correspondendo a aproximadamente $3,36 \%$ das cardiopatias congênitas.

Devido a esta raridade, viu-se a necessidade de levantar o conhecimento da equipe de saúde que recebe esse bebê com Tetralogia de Fallot e sua família, para observar como acontece esse primeiro momento tão significativo para os familiares. Para que seja possível compreender esta variável, torna-se importante investigar o conhecimento dos enfermeiros sobre a patologia.

O objetivo deste estudo foi verificar o conhecimento de enfermeiros da Maternidade e da Pediatria de um hospital geral, e enfermeiros de um Hospital Infantil do Extremo Sul Catarinense sobre a Tetralogia de Fallot.

\section{Material e métodos}

Trata-se de um estudo descritivo de abordagem qualitativa. Este tipo de pesquisa se preocupa com dados que não podem ser quantificados. Para melhoria da qualidade da análise, devido à importância da temática, optou-se por este tipo de estudo, pois se tem como objetivo descrever da melhor maneira possível a realidade do campo de pesquisa [7].

O estudo foi realizado entre março e junho de 2011, em uma maternidade e pediatria de um hospital geral e um hospital infantil, ambos do extremo sul Catarinense.

Foram alvo deste estudo dois enfermeiros do Hospital geral e nove enfermeiros do Hospital Infantil. Os participantes foram escolhidos de acordo com o local de trabalho, a partir dos seguintes critérios de inclusão: a) desejar participar da pesquisa; b) trabalhar no setor de Maternidade e Pediatria do Hospital Geral, ou trabalhar no Hospital Infantil; c) participantes que tenham assinado o Termo de Consentimento Livre e Esclarecido - TCLE; d) trabalhar na assistência aos pacientes.

Foi garantido o sigilo sobre a autoria das respostas. Os sujeitos que participaram deste estudo receberam informaçóes com o propósito da pesquisa e seus objetivos de acordo com a resoluçáo 196/ CNS/96 que estabelece normas diretrizes básicas para pesquisas com seres humanos. Esta pesquisa foi aprovada pelo comitê de ética dos hospitais onde o estudo foi realizado. Recebendo parecer favorável com o número de protocolo: 195/2011.

Os dados foram coletados a partir de entrevista semiestruturada que combina perguntas abertas e fechadas, na qual o informante tem a possibilidade de discorrer sobre o tema proposto. O pesquisador deve seguir um conjunto de questóes previamente definidas, mas ele o faz em um contexto muito semelhante ao de uma conversa informal. $\mathrm{O}$ entrevistador deve ficar atento para dirigir, no momento que achar oportuno, a discussão para o assunto que o interessa fazendo perguntas adicionais para elucidar questóes que não ficaram claras ou ajudar a recompor o contexto da entrevista. Esse tipo de entrevista é muito utilizado quando se deseja delimitar o volume das informações, obtendo assim um direcionamento maior para o tema, intervindo a fim de que os objetivos sejam alcançados [7].

Os dados foram organizados e analisados na forma de análise temática, conforme conceitua Minayo [7]:

\footnotetext{
"A noção de Tema está ligada a uma afirmação a respeito de determinado assunto. Ela comporta um feixe de relaçôes e pode ser graficamente apresentada por meio de uma palavra, frase, um resumo (...). Qualitativamente a presença de determinados temas denota os valores de referência e os modelos de comportamento presentes no discurso."
}

Sendo assim, optou-se por esta forma de análise, visto que se enquadra nos objetivos do presente estudo.

\section{Resultados e discussão}

A partir da análise das entrevistas surgiram os seguintes eixos temáticos: o conhecimento dos entrevistados a respeito da Tetralogia de Fallot; a descriçáo dos sinais e sintomas da Tetralogia de Fallot; postura dos entrevistados diante do desconhecido; a carência de informação sobre Tetralogia de Fallot; estratégias adotadas pelos entrevistados para o atendimento de pacientes cardiopatas; contato com a criança portadora de Tetralogia de Fallot; 
preparo para a atuação com crianças com Tetralogia de Fallot; estímulos para o conhecimento.

\section{Caracterização do perfil dos entrevistados}

Foram entrevistados 11 enfermeiros com idade entre 25 e 75 anos, com a mediana de 30 anos, sendo 10 do sexo feminino e um do sexo masculino. Quanto ao tempo de formação foram encontrados dados entre seis meses e 24 anos com a mediana de 4 anos e meio, já o tempo de atuação como enfermeiro esteve entre dois meses e meio e 30 anos, com mediana de 4 anos.

Somente dois entrevistados não possuem especialização, os demais relatam ter algum aperfeiçoamento científico como Pós-Graduação em Neonatologia e Pediatria, UTI, Urgência e Emergência, Oncologia, Obstetrícia, Geriatria, Naturologia Aplicada, Saúde do Trabalhador, Enfermagem Cardiológica e Mestrado.

\section{O conhecimento dos entrevistados a respeito da Tetralogia de Fallot}

Três dos enfermeiros entrevistados não souberam ou demonstraram não ter conhecimento em relação à Tetralogia de Fallot, como pode ser observado nos discursos a seguir:

"Não conheço Tetralogia de Fallot, não sei o que é [...]" (E1)

"Alguma coisa com pronúncia? Ah, eu já li alguma coisa sobre isso, mas agora vou custar a lembrar." (E2)

"Pra ti falar a verdade não recordo o que é [...]" (E3)

A maioria não conseguiu definir exatamente o que era a Tetralogia de Fallot, mas relatavam o mínimo que recordaram:

"Não sei exatamente o que é, eu sei que é uma má formação cardíaca, mas explicar como ela é, como ela funciona, como ela é diagnosticada eu não sei” (E5, E7, E11)

“É uma má formação que não consegue mandar o sangue oxigenado para o organismo" (E8, E9, E10)
Somente um dos entrevistados tinha conhecimento sobre a patologia, descrevendo os defeitos apresentados no coração:

"É uma patologia cianótica né, que envolve quatro patologias [...] tem sobreposição de grandes vasos, tem CIV, hiperplasia do ventrículo e estenose de artéria pulmonar” (E4)

Para prestar um atendimento mais qualificado ao paciente há necessidade de se conhecer a realidade da patologia diagnosticada pelo médico. Bueno e Kimura [8] relatam que "Conhecer o perfil da população com a qual se trabalha favorece a elaboração do plano assistencial pelo enfermeiro e o provimento de uma assistência adequada pela equipe de enfermagem. Assim, é possível contribuir na minimização das complicaçôes e proporcionar condiçóes favoráveis ao atendimento..."

Conforme os relatos dos entrevistados percebe-se que a maioria náo possui muitos conhecimentos sobre a patologia, o que pode desencadear um atendimento inadequado a criança portadora de Tetralogia de Fallot e a seus familiares, náo conseguindo instruí-los quando necessário.

Para se realizar uma assistência de enfermagem é necessário ter conhecimento a respeito da patologia, sua anatomia, as repercussóes na circulação e oxigenação da criança, as intervençóes cirúrgicas realizadas e o tratamento [8].

Pacientes cardiopatas submetidos à cirurgia são muito complexos e necessitam de uma equipe preparada para assisti-lo, capazes de prever e detectar complicaçóes precoces e atuar com rapidez, assim como a família necessita de explicaçóes acerca dos procedimentos realizados e o prognóstico da patologia [9].

\section{A descriçáo dos sinais e sintomas da Tetralogia de Fallot}

Para se obter uma maior visibilidade do conhecimento dos enfermeiros questionamos sobre os sinais e sintomas. Cinco dos entrevistados náo souberam ou não lembraram e os demais descreveram conforme as falas a seguir:

"Ausculta alterada e cianose de extremidades" (E7, E10)

"Cianose generalizada e uma saturação de $85,86[\ldots] ”($ E9, E6) 
"Insuficiência respiratória, eles são cianóticos, é o bebê azul [...] eles fazem saturação baixa, tem má perfusão e extremidades frias" (E4)

"A criança maior ela caminha, daí quando tu vê ela se agacha para ter uma maior circulação" (E8)

Verifica-se com os depoimentos dos entrevistados que mais da metade consegue descrever algum sinal de Tetralogia de Fallot. Isto auxilia na realização dos cuidados de enfermagem a estes pacientes, embora alguns entrevistados chegassem a estes sinais e sintomas baseados no fato de ser uma cardiopatia, conforme os mesmos relataram a pesquisadora:

"Sinais e sintomas específicos não sei, mas como é um problema cardíaco..." (E3, E5, E7, E11)

A observação de sinais e sintomas facilita o acompanhamento da evoluçáo do quadro clínico. Segundo Balduino, Mantovani e Lacerda [10] o enfermeiro "precisa saber identificá-los para manter o paciente estável, permitindo-lhe aguardar para realizar, se for o caso, um possível procedimento cirúrgico, um exame diagnóstico terapêutico ou até um procedimento intervencionista."

O sinal mais visível e perceptível na T4F é a cianose generalizada. $\mathrm{Na}$ ausculta cardíaca há presença de sopro e a saturaçáo permanece baixa devido a dificuldade de oxigenação do sangue causada pela estenose pulmonar. Crises de hipóxia são frequentes nestes neonatos [2].

\section{Postura dos entrevistados diante do desconhecido}

Para aqueles entrevistados que desconhecem a T4F, encontramos três situaçóes diferentes: uma que relata que não faria nada, uma que só presta atendimento de emergência e quatro que afirmam pesquisar sobre a patologia.

"Eu não faço nada, o pediatra encaminha para outro hospital" (E1)

"A gente tem que olhar bem, crianças cardiopatas geralmente saturam baixo [...] a gente leva para sala de emergência né [...]" (E5)
"Se aparece algum caso que desconheço, peço explicação para o médico sobre a doença e procuro ler mais [...]" (E2, E11, E3, E10, E7)

As falas dos cinco entrevistados demonstram que ao se depararem com o desconhecido eles buscam aprofundar seus saberes em relação aquela determinada patologia. Esta procura traz embasamento para melhorar o atendimento após a pesquisa, mas infelizmente ainda não é a realidade de todos os trabalhadores da saúde.

Um dos grandes desafios da atenção em saúde é ofertar uma assistência rica em conhecimentos, procedimentos e equipamentos aliada a um acolhimento das necessidades dos pacientes e de sua família [11].

Diante do choque da notícia de ter um filho com uma patologia grave como a Tetralogia de Fallot, os pais buscam informaçóes a respeito da doença e de apoio para seguir os cuidados com sua criança. Nesta procura, os profissionais da área da saúde são os mais próximos dos familiares que podem dar estas orientaçóes, criando um vínculo entre ambos que auxilia na luta pelo bem-estar do paciente [12].

Enfatiza-se aqui que para poder dar este suporte a família é necessária ter o mínimo de informação a respeito da T4F. Os enfermeiros devem estar melhorando o conhecimento, buscando estudos e atualização de conteúdo. Pesquisas são lançadas periodicamente ao alcance daqueles que querem enriquecer suas experiências.

\section{A carência de informaçáo sobre Tetralogia de Fallot}

Entende-se que a falta de informação muitas vezes pode levar a um mau atendimento ao paciente. Vemos diferentes relatos a respeito da carência de aprendizado sobre a Tetralogia de Fallot:

"Não sinto carência porque não sinto necessidade de saber" (E1)

"Acho que é de ir atrás da verdade, porque é tanta coisa que a gente tem para estudar" (E8)

"Eu acho que a gente devia se aprofundar mais assim, sobre medicaçóes, as drogas que seriam usadas [...] eu sinto carência” (E9) 
"Com certeza, na faculdade eu nem me lembro de ter estudado sobre isso" (E11)

Vê-se com as respostas dos entrevistados que há muita divergência de sentimentos em relação à carência e a necessidade de busca do saber. A ausência da necessidade de obter conhecimento é um fato preocupante, sendo que o entrevistado continuará sem conhecer a patologia no momento em que ela aparecer no seu setor.

A assistência de enfermagem deve ser realizada de forma mais humanizada com integralidade e respeito à vida. Santos e Dias [13] corroboram para isto com a seguinte afirmativa: "O enfermeiro, para efetivar, o cuidado da criança tem de compreender conceitos da área de conhecimentos específicos oriundos da psicologia, antropologia, sociologia, além dos aspectos biológicos e técnicos".

Para isso deve-se utilizar de instrumentos específicos de trabalho e força de vontade para transformar a assistência prestada hoje, para uma mais humanística. Oliveira et al. [14] afirmam que "esses instrumentos caracterizam-se como fundamentação teórica possibilitando a prática da profissão, as técnicas manuais utilizadas na assistência ao paciente e o local de trabalho".

\section{Estratégias adotadas pelos entrevistados para atendimento de pacientes cardiopatas}

Como visto em estágios da graduação, existem protocolos para alguns casos, como, por exemplo, para parada cardiorrespiratória (PCR), que este ano entra com um novo protocolo onde devem ser realizadas 100 compressóes por minuto (http:// www.heart.org). Estes auxiliam na realização de um atendimento rápido e eficaz, pois são baseados em atendimentos anteriores e comprovaçóes científicas.

Pacientes cardiopatas devem ser atendidos com rapidez e agilidade por se tratar de algo sério e de grande gravidade. Quando questionados sobre a existência de uma estratégia para estes pacientes nos seus setores encontramos as seguintes falas:

"Não tem nenhum fluxograma para atendimento destes pacientes, é observado a parte cardíaca, mas a gente não pode esquecer das outras partes." (E7)

"O protocolo é de PCR [...] a gente entra oferecendo oxigênio, já bota em monitor cardíaco... sempre que o paciente aparece com cianose a gente segue esse protocolo" (E3, E4, E9)

"A primeira coisa que a gente faz é instalar $\mathrm{O} 2$, pegar acesso venoso, tentar estabilizar essa criança e depois seguir ordem médica." (E5)

"Tem que tá observando a saturação né, criança cardiopata tem dificuldade de saturaçáo [...] na verdade a gente dá um atendimento prioritário a essa criança, ela é classificada como risco, independente se ela tá com sintomas estáveis.” (E8)

"Nossas emergências são atendidas todas do mesmo jeito [...] o médico faz encaminhamentos na aréa cardíaca só para Florianópolis, não tem cardiologista infantil aqui na regiáo" (E11)

"Geralmente as cardiopatias mais graves são encaminhadas a Porto Alegre para fazer cirurgia, ou para Florianópolis, a gente dá o primeiro atendimento e o médico encaminha." (E10, E2, E6, E1)

As falas dos entrevistados demonstram que não há um fluxograma específico para atendimento a cardiopatas, porém há relatos de que pacientes graves sáo encaminhados a outros hospitais fora da cidade pela inexistência de um profissional cardiopediatra na cidade, impossibilitando a assistência mais adequada a estes pacientes.

Para realizar a assistência de enfermagem podem ser utilizados modelos e normas para facilitar e agilizar o atendimento. Estes modelos são criados a partir de atendimentos prévios de pacientes com as mesmas características [14].

\section{Contato com criança portadora de Tetralogia de Fallot}

Dos 11 entrevistados somente dois relataram ter tido contato com pacientes portadores de Tetralogia de Fallot. Foram experiências breves mais marcantes para os entrevistados:

"Eles têm passagem rápida aqui... esse bebê que chegou ele ia ser encaminhado para 
fazer cirurgia, acho que em Santo Antônio, em Porto Alegre, daí ele fez a parada aqui né... a gente só estabilizou, eu lembro que ele estava no oxigênio mas nem foi entubado, ficou só em cateter de $\mathrm{O} 2$, tinha acho que 4 meses... era bebê assim, pequeno... em seguida já foi remanejado, já foi transferido para lá [...] Aí eu lembro de uma criança que acho que já tinha mais de um ano que já tinha correção, eu lembro que ela tinha uma cicatriz no peito, só que ela também não ficou... não veio a óbito nem nada, ela foi transferida também...esses dois casos que eu lembro, assim” (E6)

"Que eu me lembre a gente já mandou duas para Porto Alegre e já negou vaga... aí se me perguntar quantos já negamos vaga porque não tem médico, aí vou ti dizer que foram vários [...] parece que teve uma que foi a óbito mês passado, que náo deu tempo de encaminhar, mas parece que foi a óbito em outro hospital. E assim, quando os médicos sabem do diagnóstico de Tetralogia ou qualquer outra cardiopatia, eles tentam encaminhar para a UTI o mais rápido possível... o bebê tá muito mal, tá grave, precisa entrar para estabilizar para depois mandar para Porto Alegre, eles querem se livrar, por isso a gente já teve essas duas admissóes, porque náo tiveram paciência, porque para fazer a transferência intermunicipal requer um monte de papelada, tem que entrar em contato com a Secretaria de Saúde do município, que as vezes não é daqui... então é um monte de burocracia que eles não querem, né ..daí eles jogam a bomba para cá, daí a gente acaba ficando mais com essa parte infelizmente. Quando o bebê chega a gente vai lá, avalia, se tem alguma intercorrência a gente atende mas aí a gente acaba ficando com a parte burocrática, porque quem vai ter que fazer a transferência, ter que entrar em contato com a Secretaria de Saúde, Samu, fazer as ligaçóes e contatos com a outra UTI de Porto Alegre é tudo o enfermeiro né, o médico que tá de plantão aqui só fala com o médico de plantão de lá, o resto é tudo comigo, a criança só sai daqui de ambulância quando já tá tudo certinho lâ” (E4)
Experiências práticas de convivência com a patologia traz maiores conhecimentos para os enfermeiros por estarem lidando diretamente com a situação. Pesquisas relacionadas ao contato entre enfermeiros e crianças com anomalias congênitas revelam que esta assistência é desgastante emocionalmente, mas gera grande satisfação pessoal, e que, quando trabalhado em equipe, juntamente com o conhecimento teórico, as dificuldades podem ser superadas com maior facilidade e até mesmo minimizadas [12].

A incidência de casos de Tetralogia de Fallot demonstra-nos que a necessidade de se ter embasamento teórico sobre a patologia amplia-se cada vez mais. Estudos realizados no Sul do Brasil mostram um índice de 6,9\% de casos entre 1.961 pacientes pesquisados com cardiopatia congênita no período de janeiro de 1995 a dezembro de 1997, no hospital infantil do Paraná [6].

\section{Preparo para a atuaçáo com crianças com Tetra- logia de Fallot}

Foram encontradas três realidades distintas quanto ao sentimento de capacidade de atendimento ao portador de T4F: existem aqueles que não se sentem preparados, os que estáo seguros para cumprir seu papel de enfermeiro e aqueles que se sentem inseguros, confirmados pelos relatos a seguir:

"Não me sinto preparada né, não conheço a doença" (E2)

"Assim que o paciente chega não, mas depois que souber o diagnóstico sim, a gente corre atrás do melhor cuidado" (E7)

"Eu me sinto preparada para tudo, para atender todas as emergências que chegam aqui [...] acho que na profissão da gente tem que fazer o melhor que a gente pode. Eu me sinto preparada para atender tudo que acontece aqui dentro, claro que às vezes a gente atua de um modo melhor, numa intercorrência ou outra deixa a desejar, mas é por isso que a gente tem que correr atrás e estudar, ver o que errou, e não só o enfermeiro, porque o enfermeiro ele dá a postura para a própria equipe" (E11).

Conforme os relatos dos entrevistados percebe-se que a preocupação maior dos enfermeiros é dar 
suporte de assistência a vida, porém não é somente este o papel da enfermagem no atendimento pediátrico. A equipe que estará atuando junto ao paciente deve ter conhecimento teórico sobre a patologia para poder dar, além do assistencialismo, um apoio à família neste momento de extremo desconforto e angústia familiar.

"A conduta dos profissionais de saúde, diante do recém-nascido portador de malformação congênita deve ser específica e de qualidade. Assim, os conhecimentos sobre as malformaçôes e as condutas a serem adotadas pelos enfermeiros e demais membros da equipe, são de suma importância no sentido de orientar pais e familiares, permitindo que estes esclareçam suas dúvidas sobre a deficiência e sintam-se encorajados a buscarem qualidade de vida dentro dos limites impostos à criança." [13].

Podemos observar na prática de muitos enfermeiros a tentativa de prestar um atendimento mais humanizado. Referente a isso, Guiller, Dupas e Pettengill [12] afirmam que mesmo que o enfermeiro tente incluir a família em sua prática assistencial, ainda existem lacunas no conhecimento, principalmente em relação as intervençóes de enfermagem. E esta falta de saber leva a uma família mal esclarecida a respeito da saúde de sua criança.

Para prestar um atendimento integral é necessário que o profissional de saúde saiba o que está acontecendo, e quais instrumentos utilizar em seu trabalho para produzir uma assistência de qualidade, estabelecendo uma confiança entre paciente/ familiares e equipe de enfermagem [14].

\section{Estímulos para o conhecimento}

Um dos aspectos mais positivos desta pesquisa foi ver a realidade dos hospitais frente ao estímulo para o conhecimento. Todos os entrevistados relataram ter reunióes mensais que trazem assuntos desde as patologias mais frequentes até as novas técnicas idealizadas para a saúde.

"A gente tem educação continuada. É sempre feito um mural quinzenal ou mensal que sempre lembra uma patologia ou cuidado específico para o recém-nascido. A gente faz um estudo né, divide entre os enfermeiros, lê, estuda e fala para a equipe." (E10)
"A gente tá sempre com curso de administração de medicação, diluição de medicação. Sempre tem incentivo para o profissional tá aprendendo, sempre tem, só não cresce, não aprende quem não quer." (E11)

A educação continuada criada em 1920 vem sendo de grande importância para a enfermagem. Ela é caracterizada por um processo permanente de educação, trazendo enriquecimento aos conhecimentos da formação básica, objetivando melhorar e atualizar a capacitação dos profissionais. Ela ainda pode ser descrita como "aquela que capacita à pessoa não só para as mudanças desejadas pela instituição como também para as requeridas pela sociedade, desenvolvendo-a como pessoa e como profissional." [15].

Acredita-se que a grande maioria dos hospitais busca levar para sua instituição a educação continuada, o que favorece muito a busca de conhecimentos da equipe profissional de saúde, que irá acarretar em um melhor atendimento aos pacientes.

\section{Conclusão}

O momento de maior angústia vivenciado pelos pais de um portador de T4F ocorre dentro de uma unidade hospitalar, sendo a equipe de enfermagem de suma importância neste processo. É ela juntamente com uma equipe multidisciplinar capacitada quem dará o suporte e apoio tanto emocional quanto prático ao paciente e seus familiares. A realidade encontrada no campo de estudo demonstra a falta dessa capacidade de fornecer suporte no momento da entrada do paciente no hospital.

Com essa observação nos questionamos: será que esta é a realidade de muitos hospitais? Esta situação se repete para outras patologias tão graves quanto a Tetralogia de Fallot?

Diante da dificuldade de encontrar literatura sobre o assunto, sugere-se a realizaçáo de novos estudos sobre a patologia, aumentando o conhecimento dos profissionais de saúde e até mesmo de familiares de portadores de T4F que hoje buscam o maior número de informaçóes acerca da patologia.

Sugere-se também a inclusão do tema Tetralogia de Fallot, assim como outras patologias graves, nos cursos de capacitação e na educação continuada das instituiçóes para obter uma assistência mais qualificada a estes pacientes. É importante nestas 
capacitaçóes estimularem o cuidado humanístico, integrando a família na assistência.

Para as universidades sugere-se que o conteúdo seja mais bem esclarecido em sala de aula e mais exigido dos acadêmicos, para fazer com que estes futuros enfermeiros saiam do ambiente acadêmico com um bom embasamento teórico das mais complexas patologias.

\section{Referências}

1. Ribeiro C, Madeira AMF. O significado de ser mãe de um filho portador de cardiopatia: um estudo fenomenológico. Rev Esc Enferm USP 2006;40:42-9.

2. Lopez FA, Campos Junior D. Reconhecimento e conduta nas Cardiopatias Congênitas. In: Miyague NI, Binotto CN, Mateus SMC. Tratado de pediatria: Sociedade Brasileira de Pediatria. 2a ed. Baurueri: Manole; 2010. p.631-58.

3. Kenner C. Enfermagem neonatal. $2^{a}$ ed Rio de Janeiro: Reichmann \& Affonso; 2001. 375 p.

4. Rivera IR. Cardiopatia congênita no recém-nascido: da solicitaçáo do pediatra à avaliaçáo do cardiologista. Arq Bras Cardiol 2007;89:6-10.

5. Schneider DG. Acolhimento ao paciente e família na unidade coronariana. Texto Contexto Enferm 2008;17:81-90.

6. Miyague NI, Cardoso SM, Meyer F, Ultramari FT, Araújo FH, Rozkowski I et al. Cardiopatias congê- nitas na infância e adolescência. Arq Bras Cardiol 2003;80:269-73.

7. Minayo MCS. Pesquisa social: teoria, método e criatividade. 23a ed. Petrópolis: Vozes; 2004. 80 p.

8. Bueno M, Kimura AF, Pimenta CAM. Avaliação da dor em recém-nascidos submetidos à cirurgia cardíaca. Acta Paul Enfermagem 2007;20:428-33.

9. Rocha DLB, Zagonel IPS. Modelo de cuidado transicional à máe da criança com cardiopatia congênita. Acta Paul Enferm 2009;22:243-9.

10. Balduino AFA, Mantovani MF, Lacerda MR. O processo de cuidar de enfermagem ao portador de doença crônica cardíaca. Esc Anna Nery Rev Enferm 2009;13:342-51.

11. Lamego DTC, Deslandes SF, Moreira MEL. Desafios para a humanização do cuidado em uma unidade de terapia intensiva neonatal cirúrgica. Ciênc Saúde Coletiva 2005;10:669-75.

12. Guiller CA, Dupas G, Pettengill MAM. Criança com anomalia congênita: estudo bibliográfico de publicaçōes na área de enfermagem pediátrica. Acta Paul Enferm 2007;20:18-23.

13. Santos RS, Dias IMV. Refletindo sobre a malformação congênita. Rev Bras Enferm 2005;58:592-6.

14. Oliveira BRG, Lopes TA, Viera CS, Collet N. O processo de trabalho da equipe de enfermagem na UTI neonatal e o cuidar humanizado. Texto Contexto Enfermagem 2006;15:105-13.

15. Souza MGG, Cruz EMNT, Stefanelli MC. Educação continuada em enfermagem psiquiátrica: reflexão sobre conceitos. Rev Esc Enferm USP 2006;40:105-10. 